\title{
POLYANILINE RETAINED GLASS TEMPLATES AS SENSORS FOR ACIDIC/ BASIC AND/OR REDOX GASES
}

\author{
R.M.G. RAJAPAKSE*, A.D.L. CHANDANI PERERA and H.D.S. PREMASIRI* \\ Department of Chemistry, University of Peradeniya, Peradeniya.
}

(Received: 17 August 2000 ; accepted: 26 March 2001)

\begin{abstract}
Polyaniline is a conducting polymer that can exist in six different stiuctural forms depending upon the extent of oxidation and the protonation of the polymer. These forms have their own characteristic physical properties such as colour and electronic conductivity. The different forms can be interconverted by suitable acid/ base and/oredox treatments. The use of this fact to devise sensors for acidbase and/ or redox gases using an array of different forms of polyaniline retained glass plates is clescribed in this article.
\end{abstract}

Keywords: Acidichasic gases, gas sensors, polyaniline, polyaniline retained glasses, redox gases.

\section{INTRODUCTION}

Polyaniline (PANI) has received a great deal of academic and industrial scientific interest as one of the promising conductive polymers that is attractive for severa] technological applications. These include their use as electrodes in rechargeable batteries, electrochromic devices, information memories, electrocatalysts and liquid crystal display devices. ${ }^{1,2}$ This polymer can be prepared by electropolymerisation or by chemical polymerisation from an aqueous or non-aqueous acidic solution. The polymer can be chemically attached to glass surfaces to give materials with a surface electronic conduction. ${ }^{3,4}$

The polymer can exist in six different structural forms with the stability of a given form depending upon the extent of protonation and the oxidation of the polymer. chains. The six forms are inter-convertible and their physical characteristics are summarised in Table 1. As can be clearly seen from this table, the different forms of the polymer are stable under different acidic/basic and redox conditions. This, by exposing a selected form of the polymer to gases with acidic, basic, reducing, oxidising, acidic and reducing or oxidising and acidic properties, it should be possible to convert the chosen form of the polymer to different forms with a concomitant change in colour and conductivity. This property of the polymer has already been utilised in devising $\mathrm{pH}$ sensors, ${ }^{5}$ sensors for various other ions ${ }^{6-8}$ and also for $\mathrm{NH}_{3}$ gas. ${ }^{0,11}$ However, we show below that this polymer can be used to sense not only a single ionic or gaseous species but can also be used to devise a sensor for various species having acid/base and/or redox properties. The different species can be distinguished and measured separately.

" Corresponding author. 
Table 1: Physical properties of six structural forms of polyaniline.

\begin{tabular}{|c|c|c|c|c|}
\hline Polymer & $\begin{array}{l}\text { Acidity of the } \\
\text { medium }\end{array}$ & $\begin{array}{l}\text { Extent of } \\
\text { oxidation }\end{array}$ & Colour & $\begin{array}{c}\text { Electronic } \\
\text { conductivity } \\
\mathrm{Scm}^{-1} \\
\end{array}$ \\
\hline $\begin{array}{l}\text { Leuco- } \\
\text { emeraldine salt }\end{array}$ & $\begin{array}{l}\text { Highly acidic } \\
\text { medium } \mathrm{pH}<3\end{array}$ & $\begin{array}{l}\text { Unoxidised, } \\
\text { protonated } \\
\text { polymer }\end{array}$ & $\begin{array}{c}\text { Transparent } \\
\text { Yellow }\end{array}$ & $\begin{array}{l}\text { Insulator } \\
\text { ca. } 10^{-12}\end{array}$ \\
\hline $\begin{array}{l}\text { Leuco- } \\
\text { emeraldine base }\end{array}$ & $\begin{array}{l}\text { Weakly acidic, } \\
\text { neutral or } \\
\text { basic medium } \\
\text { pH>3 }\end{array}$ & $\begin{array}{l}\text { Unoxidised } \\
\text { deprotonated } \\
\text { polymer }\end{array}$ & Yellow & $\begin{array}{l}\text { Insulator } \\
\text { ca. } 10^{-12}\end{array}$ \\
\hline Emeraldine base & $\begin{array}{l}\text { Weakly acidic, } \\
\text { neutral or } \\
\text { basic medium } \\
\text { pH>3 }\end{array}$ & $\begin{array}{c}\text { Partially } \\
\text { oxidised } \\
\text { deprotonated } \\
\text { polymer }\end{array}$ & Blue & $\begin{array}{l}\text { Insulator } \\
\text { ca: } 10^{-12}\end{array}$ \\
\hline Emeraldine salt & $\begin{array}{l}\text { Highly acidic } \\
\text { medium } \mathrm{pH}<3\end{array}$ & $\begin{array}{l}\text { Partially } \\
\text { oxidised } \\
\text { protonated } \\
\text { polymer }\end{array}$ & Green & $\begin{array}{c}\text { Electronic } \\
\text { conductor } \\
10^{-4}-10^{2}\end{array}$ \\
\hline $\begin{array}{l}\text { Pernigraniline } \\
\text { base }\end{array}$ & $\begin{array}{l}\text { Weakly acidic, } \\
\text { neutral or } \\
\text { basic medium } \\
\text { pH }>3\end{array}$ & $\begin{array}{c}\text { Fully oxidised } \\
\text { deprotonated } \\
\text { polymer }\end{array}$ & Violet & $\begin{array}{l}\text { Insulator } \\
\text { ca. } 10^{-12}\end{array}$ \\
\hline $\begin{array}{l}\text { Pernigraniline } \\
\text { salt }\end{array}$ & $\begin{array}{l}\text { Highly acidic } \\
\text { medium } \mathrm{pH}<3\end{array}$ & $\begin{array}{l}\text { Fully oxidised } \\
\text { protonated } \\
\text { polymer }\end{array}$ & Violet & $\begin{array}{l}\text { Insulator } \\
\text { ca. } 10^{-12}\end{array}$ \\
\hline
\end{tabular}

In our work, we have exposed different forms of polyaniline attached on to surfaces of glasses to gases such as $\mathrm{Cl}_{2}, \mathrm{HCl}, \mathrm{H}_{2} \mathrm{~S}, \mathrm{NH}_{3}$, and the changes of colour and conductivity upon exposure were determined. In this way, it is possible to qualitatively identify the different types of gases using the polyaniline sensor. Furthermore, the extents of changes in each case were dependent upon the amount. of a given gas to which the polyaniline plate was exposed. Hence, the same material may also be used to quantitatively measure the above gases.

\section{METHODS AND MATERIALS}

All chemicals used were of Analar grade and were purchased from Aldrich. The aniline used was distilled under nitrogen. The glass plates used to attach polyaniline on their surfaces were of high-quality pre-cleaned glasses. Polyaniline attachment 
to glass surfaces was done as described elsewhere. ${ }^{3,4}$ The as-prepared glass plates according to the method $\mathrm{d}^{3}$ were green in colour with a resistivity of $120 \mathrm{k} \Omega \mathrm{cm}^{-1}$ while those prepared by the other method ${ }^{4}$ were also green in colour with an improved conductivity (resistivity $=12 \mathrm{k} \Omega \mathrm{cm}^{-1}$ ). The polymer in these cases was therefore, in its emeraldine salt form. The other forms of the polymer retained glass plates were prepared by necessary acid/base or redox treatment of the emeraldine salt retained glass plates. Polyaniline retained glass plates were dried for several days in a dry desiccator. The electrical connections to the glass plates were through two tight copper clips fixed to the plates within a $1 \mathrm{~cm}$ distance, each soldered to a copper wire. The desiccator was connected to a vacuum manometer and evacuated. Measured volumes of the selected gas were introduced to the desiccator through a drying tube. The conductivity and the colour of the polyaniline retained glass plates were determined as a function of the partial pressure of the gas in each case.

\section{RESULTS}

Table 2 summarises the qualitative results obtained when the polyaniline plates were exposed to the above gases. The quantitative estimation of $\mathrm{NH}_{3}, \mathrm{HCl}, \mathrm{H}_{2} \mathrm{~S}$ and $\mathrm{Cl}_{2}$, when they are alone, using different forms of polyaniline are shown in figures 1-4 respectively. Exposure of emeraldine salt retained glass plates to $\mathrm{NH}_{3}$ gas resul.ts in the increase of resistivity as depicted in figure 1 . When the emeraldine salt retained glass plates prepared according to the procedure" and subsequently immersed in a dilute alkali solution to give a greenish-blue colour with a high resistivity are exposed to $\mathrm{HCl}$, the conductivity is increased in a systematic way as shown in figure 2 . In the case of an acidic and reducing gas such as $\mathrm{H}_{2} \mathrm{~S}$, it would be better to use a fully oxidised violet pernigraniline base form of polyaniline since only gases with these properties can change the conductivity and the colour of the polymer. Thus, the polyaniline coated glass plates were first deprotonated by treating with $\mathrm{NaOH}$ until they became blue and non-conducting. The materials were then further oxidised using an aqueous $\mathrm{Fe}^{3+}$, and the resulting violet polymer was washed several times with double distilled water and dried in a dry desiccator. Figure 3 depicts the results obtained. For an oxidising and neutral gas such as $\mathrm{Cl}_{2}$ the best form of polyaniline that can be used for quantitative estimation of the gas is emeraldine salt. The results obtained for such polymer-retained glasses when exposed to different doses of $\mathrm{Cl}_{2}$ are shown in figure 4.

\section{DISCUSSION}

The results summarised in Table 2 may be explained as follows. Since the protonated salt form and the deprotonated base form of the leuco-emeraldine have the same colour (yellow) and both forms are electrical insulators, when leuco-emeraldine salt form attached glass plates are exposed to acidic $(\mathrm{HCl})$, basic $\left(\mathrm{NH}_{3}\right)$ or reducing and acidic $\left(\mathrm{H}_{2} \mathrm{~S}\right)$ gases there will be no change in colour or measurable electronic conductivity. However, when the same form of the polymer is exposed to an oxidising 
gas such as $\mathrm{Cl}_{2}$, the polymer gets oxidised. The results also show that $\mathrm{Cl}_{2}$ gas being a powerful oxidising agent, oxidises the polymer to its electronically conducting gxeen emera]dine salt form if exposed to a low dose but to an insulating violet pernigraniline salt form if exposed to a sufficiently high dose. This suggests that the oxidation of the polymer chains by a chemical oxidant takes place throughout the polymer chains as in a homogeneous reaction as opposed to electrochemical oxidation in which the propagation of conductive zones along the polymer chain starting from the electrode surface has been proposed. ${ }^{11}$ Thus, from an array of glass plates containing different forms of polyaniline, the plate with leuco-emeraldine salt form is capable of distinguishing the oxidising gases from reducing, acid or acidic and reducing gases.

The colour changes observed with emeraldine salt retained glass plates are different for the four different types of gases. Hence, using the emeraldine salt form retained glass plates, the gases may be identified when they are in isolation.

Table 2: The change of conductivity and the colour of some polyaniline forms attached glass plates upon exposure to gases such as $\mathrm{Cl}, \mathrm{HCl}, \mathrm{H}_{2} \mathrm{~S}$ and $\mathrm{NH}_{3}$.

\begin{tabular}{|c|c|c|c|}
\hline Polymer form & Gas exposed & Colour change & Conductivity change \\
\hline $\begin{array}{l}\text { Leuco-emeraldine } \\
\text { salt }\end{array}$ & $\mathrm{NH}_{3}, \mathrm{HCl}$ and $\mathrm{H}_{2} \mathrm{~S}$ & $\begin{array}{l}\text { Yellow to green at } \\
\text { low concentration. } \\
\text { Yellow to violet at } \\
\text { high concentration. }\end{array}$ & $\begin{array}{l}\text { Drastic increase at } \\
\text { low concentration. } \\
\text { Drastic increase } \\
\text { followed by drastic } \\
\text { decrease at high } \\
\text { concentration. } \\
\text { Not measurable }\end{array}$ \\
\hline Emeraldine salt & $\begin{array}{l}\mathrm{Cl}_{2} \\
\mathrm{NH}_{3} \\
\mathrm{HCl} \\
\underset{2}{\mathrm{H} \mathrm{S}}\end{array}$ & $\begin{array}{l}\text { Green to violet } \\
\text { Green to blue } \\
\text { No change } \\
\text { Green to yellow }\end{array}$ & $\begin{array}{l}\text { Drastic decrease. } \\
\text { Drastic decrease. } \\
\text { Slight increase. } \\
\text { Slight increase } \\
\text { followed by drastic } \\
\text { decrease. }\end{array}$ \\
\hline Emeraldine base & $\begin{array}{l}\mathrm{Cl}_{2} \\
\mathrm{NH}_{3} \\
\mathrm{HCl} \\
\mathrm{H}_{2}^{\mathrm{S}}\end{array}$ & $\begin{array}{l}\text { Blue to violet } \\
\text { No change } \\
\text { Blue to green } \\
\text { Blue to yellow }\end{array}$ & $\begin{array}{l}\text { Not measurable. } \\
\text { Not measurable. } \\
\text { Drastic increase. } \\
\text { Not measurable. }\end{array}$ \\
\hline Pernigraniline base & $\mathrm{Cl}_{2}, \mathrm{NH}_{3}, \mathrm{HCl}$ & $\begin{array}{l}\text { Violet to green at } \\
\text { low concentration } \\
\text { Violet to yellow at } \\
\text { high concentraion } \\
\text { No change }\end{array}$ & $\begin{array}{l}\text { Drastic increase } \\
\text { Drastic increase } \\
\text { followed by drastic } \\
\text { decrease. } \\
\text { Not measurable }\end{array}$ \\
\hline
\end{tabular}




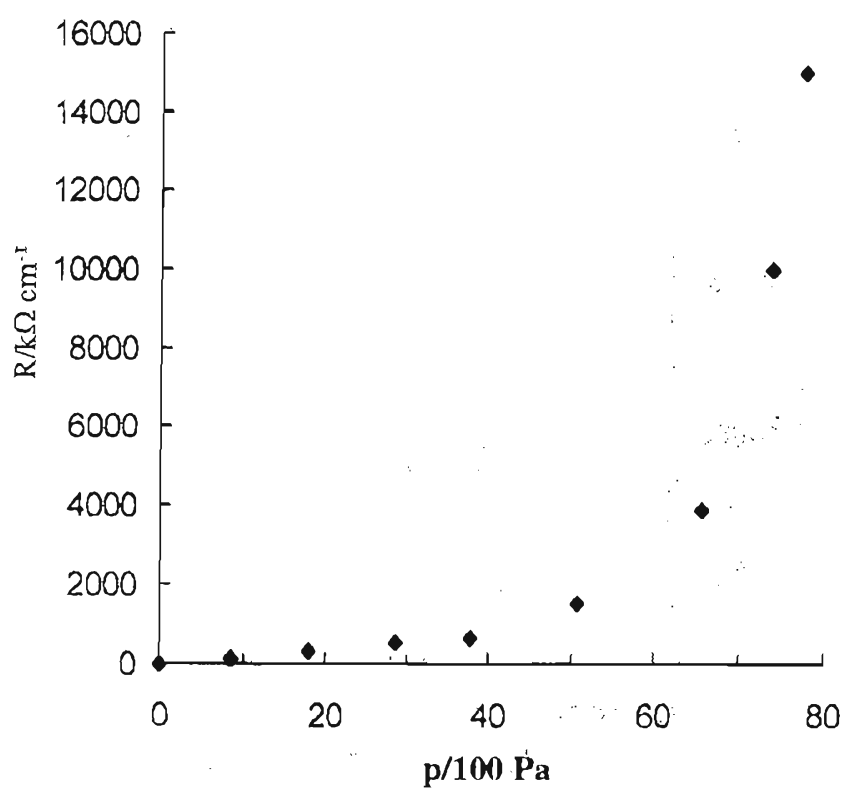

Figure 1: Resistivity of green polyaniline retained glass, $R$, versus the partial pressure of $\mathrm{NH}_{3}$ gas,p.

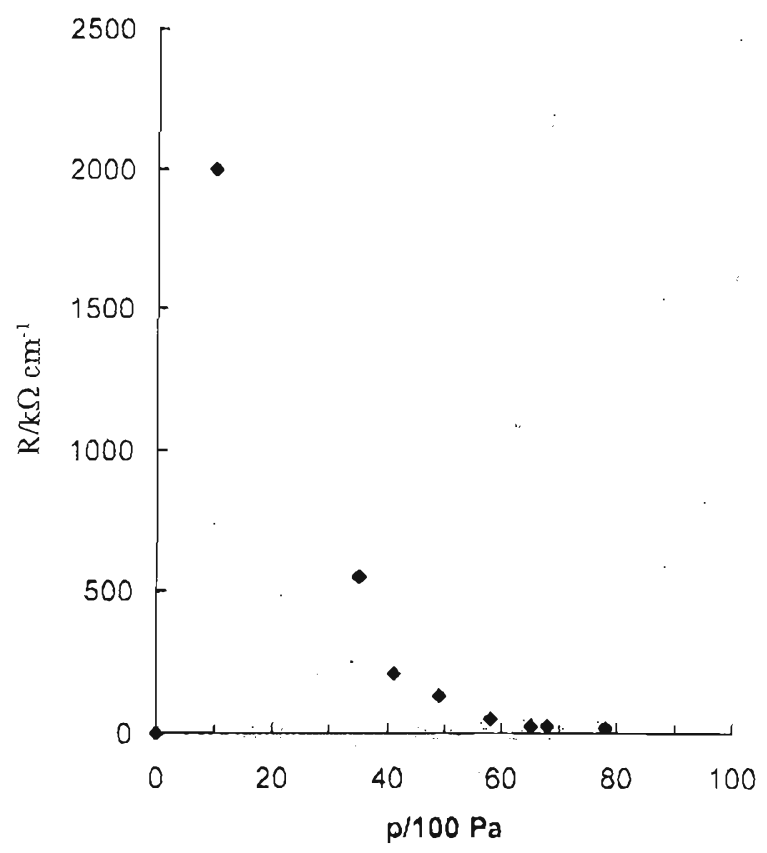

Figure 2: Resistivity of greenish-blue polyaniline retained glass, $R$, versus the partial pressure of $\mathrm{HCl}$ gas,p. 


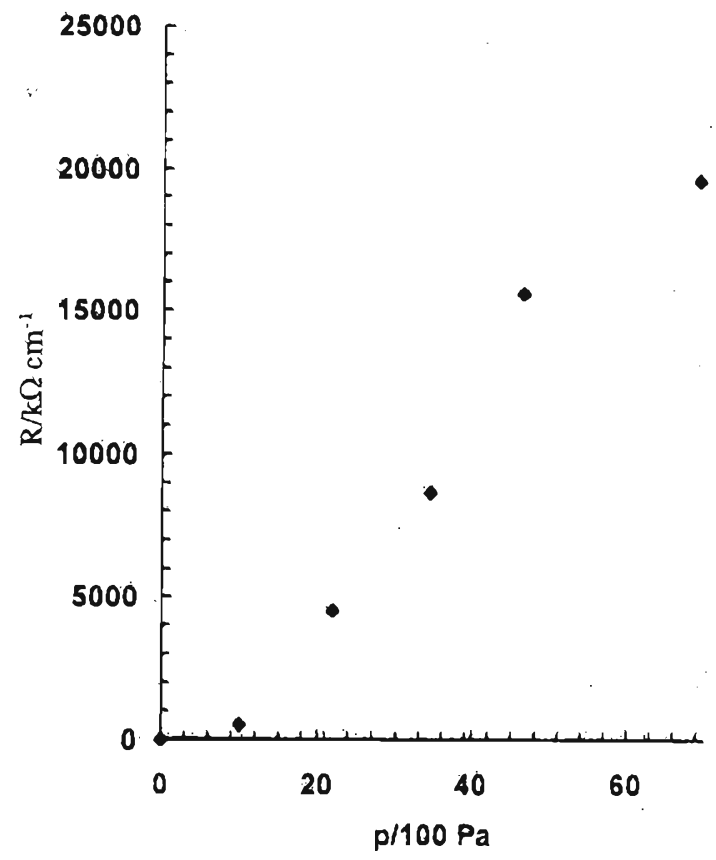

Figure 3: Resistivity of greenish-blue polyaniline retained glass, $R$, versus the partial pressure of $\mathrm{H}_{2} \mathrm{~S}$ gas,p.

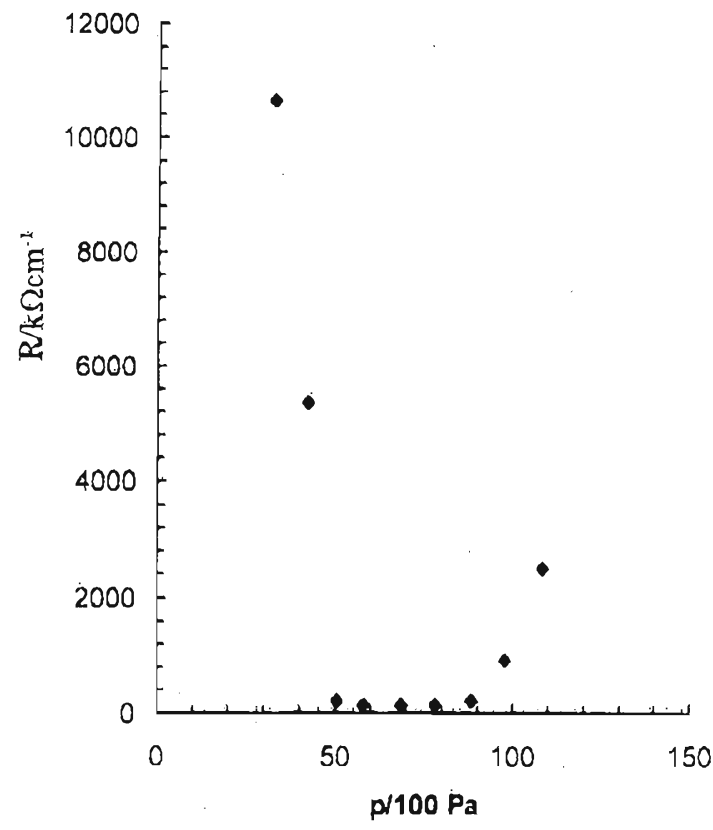

Figure 4: Resistivity of emeraldine salt retained glass plates as a function of the partial pressure of exposed $\mathrm{Cl}_{2}$ gas,p. 
A drastic increase in conductivity of the emeraldine base (blue) retained plates is only obtained if the plates are exposed to an acidic non-redox gas such as $\mathrm{HCl}$ fumes. Thus, the non-redox acidic gases may be distinguished from others using an emeraldine base retained glass plates. However, it should be mentioned that the polyaniline layers retained on glass plates by the methods ${ }^{3,4}$ above are stable only under acidic or neutral conditions. When the glass plate containing polyaniline firmly retained is treated with a concentrated solution of $\mathrm{NaOH}$ for a relatively longer period (more than 6 hours) the polymer layer begins to peel off. Thus if one wants to use the emeraldine base retained glass plates (blue) one has to start with the emeraldine salt retained plates (green) and treat with an alkali just prior to use. The peel off of the polymer when treated with $\mathrm{NaOH}$ may be due to the base hydrolysis of Si-N bonds that are likely to be the polymer/glass attachment site. Only the gases with both acidic and reducing properties, such as $\mathrm{H}_{2} \mathrm{~S}_{\text {, can change }}$ the conductivity of the pernigraniline base. Thus the pernigraniline base coated glass plates are capable of distinguishing the reducing and acidic gases from other gases. In the case of $\mathrm{NH}_{3}$, detectable conductivity changes and colour changes of polyaniline retained glass plates upon exposure to different, doses of the gas can be seen clearly if the green emeraldine salt form of the polymer is used. As seen from Figure 1, a systematic increase in resistivity, i.e., decrease in electronic conductivity, can be observed when the partial pressure of ammonia is increased. The plot may be used as a calibration curve to determine the partial pressure and hence the amount of ammonia. The colour change is from greenish violet to blue.

When partially deprotonated emeraldine salt form is exposed to an acidic gas such as $\mathrm{HCl}$ fumes, the conductivity of the polymer will be increased. This is due to the fact that the polymer films in this state can get protonated upon exposure to an acidic and non-redox gas. In fact, when the emeraldine chloride form retained glass plates are dried for several days, the colour changes gradually from green to greenish blue with simultaneous reduction in conductivity due to the removal of protons as $\mathrm{HCl}$ fumes. Thus, the dry film of emeraldine chloride can get protonated when exposed to $\mathrm{HCl}$ giving a higher conductivity and the trend seen in figure 2 is due to this reason.

The exposure of the pernigraniline base form of polyaniline to various doses of $\mathrm{H}_{2} \mathrm{~S}$ gas results in an initial decrease followed by an increase of the resistance showing that the initial protonation of the emeraldine base gives emeraldine salt at low doses but the reduction also takes place to give leuco-emeraldine salt form when higher doses are administered.

As shown in figure 4, when emeraldine salt is exposed to an oxidising gas such as $\mathrm{Cl}_{2}$ the polymer gets oxidised resulting in the reduction of its conductivity. At a sufficiently high dose, the polymer turns violet and then its conductivity cannot be measured. 
The exposure of sensory materials to a mixture of gases is next considered. It is worth mentioning here that most gases, which are active towards polyaniline sensor, are mutually reactive and hence it is very unlikely that they would coexist. For example, detection of components in a mixture containing acidic (e.g. $\mathrm{HCl}$ ) and basic (e.g., $\mathrm{NH}_{3}$ ) would not arise in reality. The situation is the same for reducing and oxidising gases. So the problem now reduces to the practical situation of mixtures having non-reactive gaseous components. These components would most probably show similar behaviour towards the polymer and hence the identification of components would not be realistic. Consider, as an example, a mixture that could contain $\mathrm{Cl}_{2}, \mathrm{Br}_{2}$ and $\mathrm{I}_{2}$ gases. Both $\mathrm{Cl}_{2}$ and $\mathrm{Br}_{2}$ are capable of oxidising both leucoemeraldine salt and emeraldine salt to their highest oxidised pernigraniline state. However, the redox potential of $\mathrm{I}_{2}\left(0.536 \mathrm{~V}\right.$ at $\left.25^{\circ} \mathrm{C}\right)$ is such that it can only oxidise leuco-emeraldine into emeraldine salt but its further oxidation into pernigraniline is not possible. However an array of sensors having different forms of polymers would not distinguish the components. Nevertheless, the sensors are attractive for both qualitative identification and quantitative determination of individual gases.

\section{Acknowledgement}

Research support from the National Science Foundation (formerly NARESA) (RG/ 98/P/05 and RG/98/C/01) and SAREC Spare Parts Fund is gratefully acknowledged.

\section{References}

1 Evans P.G. (1985). The Electrochemistry of Conducting Polymers. In: Instrumental methods in Electrochemistry. (Ed. Southampton Electrochemistry Group) pp 178-185. Ellis Horwood Ltd., Chichester.

2 McDiarmid A.G., Somasiri N.L.D., Salaneck W.R., Lundstrom I., Liedberg B., Hasan M.A, Erlandsson R., and Konrasson P. (1985). In: Springer Series in. Solid State Sciences pp 218-, Springer, Berlin.

3 , Rajapakse R.M.G., Chandani A.D.L., Lankeshwara L.P.P. \& Kumarasiri N.L.W.L. (1996). Retention of polyaniline on glass functionalised with aniline. Synthetic Metals, 83:73-76.

4 Rajapakse R.M.G. and Wickramanayake D.K.W.W.M.S. (1999). An improved method for retaining polyaniline on glass surfaces. J. Natn. Sci. Foundation, Sri Lanka 27(4): 265-276.

5 Van der Leur R.H.M., Van der Waal A. and de Hann P.H. (1997). Polyaniline: A conducting polymer for $\mathrm{pH}$ sensors. Proceedings of $5^{\text {th }}$ European Conference on Advanced Materials, Processes and Applications, 3:3/463-3/466. 
6 Prakash R. and Santhanam K.S.V., (1998). Electrochromic window based on polyaniline. J. Solid state electrochemistry, 2(2): 123-125.

7 Li X. \& Li X., (1997). Polyaniline electrode as a detector for electroinactive anions. Gungneng Cailiao, 28(3): 328-330.

8 Zhou D. M., XuHong J. J., Chen Y. \& Fang Q. H., (1997). Ascorbate sensor based on "self-doped" polyaniline. Electroanalysis, 9(15): 1185-1188.

9 Masau A., Keisuke Y., Yoshihiro U. \& Akira., Japanese Patent, Kokai Tokyo Koho, JP 07 86,093.

10 Dawan S. K., Kumar D., Ram .K., Chandra S. \& Irivedi D. C., (1997). Application of conducting PANI as sensor material for ammonia. Sensors and Actuators, B40: 99-103.

11 Lyons M. E. G. (1994). Charge percolation in electroactive polymers.( Ed. M.E.G.) Lyons In: Electroactive polymer Electrochemistry pp 1-226, Plenum Press, USA. 